\title{
PART A
}

Biochemistry, Molecular \& Cell Biology,

Electrophysiology, Morphology 


\title{
THE SCOTOPIC THRESHOLD RESPONSE OF THE CAT ERG IS SUPPRESSED SELECTIVELY BY GABA AND GLYCINE
}

\author{
Frank NaArendorp and Paul A. Sieving* \\ Department of Ophthalmology, W. K. Kellogg Eye Center, University of Michigan, Ann Arbor, \\ MI 48105, U.S.A.
}

(Received 22 December 1989; in revised form 23 April 1990)

\begin{abstract}
Corneal electroretinograms (ERGs) were recorded from anesthetized cats under scotopic conditions. We examined whether the scotopic threshold response (STR) of the ERG could be functionally distinguished from scotopic PII and $a$-wave using intravitreal application of neuroactive agents. We found that neurotransmitters with active sites on third order neurons had several different effects. Results were: (1) glycine and $\gamma$-amino butyric acid (GABA) selectivity suppressed the STR but had relatively small and/or opposite effects on PII; (2) serotonin, acetylcholine and dopamine were nonselective and suppressed both STR and PII; (3) strychnine blocked the suppression of the STR by glycine. GABA-a antagonists alone only partially blocked GABA effects on the STR, and GABA-b antagonists were ineffective; (4) strychnine enhanced the STR. Bicuculline also increased STR amplitudes, but only in the presence of haloperidol. Our results suggest that the retinal pathway that contributes to the rod-driven STR is strongly influenced by cells that release glycine or GABA in the dark. These cells are possibly third order neurons in the retina. Our results also suggest that picrotoxin and bicuculline can facilitate the release of dopamine in the cat retina. Furthermore, the data indicate a light evoked release of dopamine which was first noticeable at about two log units above ERG threshold.
\end{abstract}

Retina Electroretinogram Scotopic Glycine GABA Amacrine cell Dopamine ERG Vision

\section{INTRODUCTION}

It has been known for many years that various components of the electroretinogram (ERG) can be affected selectively by specific pharmacological agents. The differential chemical sensitivities of these various ERG components may reflect differences in their cellular sources or mechanisms. For example, the photoreceptor $a$-wave and slow PIII can be separated from PII and $c$-wave in the isolated retina by aspartate which prevents transmission of signals between photoreceptors and second order neurons (Sillman, Ito \& Tomita, 1969). 2-Amino-4-phosphonobutyric acid (APB) selectively blocks the light response of depolarizing bipolar cells (Massey, Redburn \& Crawford, 1983; Slaughter \& Miller, 1981) and suppresses PII which is thought to originate from Müller cells in response to $\mathrm{K}^{+}$released from depolarizing bipolar cells (Knapp \& Schiller, 1984; Stockton \& Slaughter, 1989). In frog and rabbit, GABA modulates the extracellular $\mathrm{K}^{+}$concentration

\footnotetext{
*To whom reprint requests should be addressed.
}

differentially in the distal and the proximal retina, thereby influencing PII amplitude (Dick \& Miller, 1985a, b). GABA-sensitive amacrine cells in mudpuppy have been implicated in generating oscillatory potentials that ride on photopic PII (Wachtmeister \& Dowling, 1978; Wachtmeister, 1980).

Recent studies investigating the origin of the scotopic threshold response (STR) of the cat ERG (Sieving, Frishman \& Steinberg, 1986; Sieving, Wakabayashi \& Lemon, 1988) implicated the proximal retina as the likely origin for this component. Most recently, Frishman and Steinberg (1989) revealed a light-dependent proximal $\mathrm{K}^{+}$increase manifest near absolute threshold with a time course and saturation level very similar to the STR. The STR of human, monkey and cat appears below PII threshold in relative isolation from other ERG components (Sieving \& Nino, 1988; Wakabayashi, Gieser \& Sieving, 1988). Saturation of the STR occurs at a lower illuminance level than rod-saturation (Sieving et al., 1986). Using intravitreal aspartate, we provided additional evidence that the STR of cat and monkey most 
likely derives from post-photoreceptoral neurons (Wakabayashi et al., 1988). Collectively, these reports are consistent with the notion of a proximal retinal origin for the STR. Our preliminary results indicated that APB suppressed both PII and STR without influencing the implicit time of the $a$-wave, which leaves depolarizing bipolar cells as well as other proximal neurons that respond to the onset of dim light as candidate sources for the STR. Ganglion cells, however, may not contribute directly to the ERG waves (Noell, 1954), including the STR (Sieving, 1990). Thus existing evidence favors the inner nuclear-inner plexiform retina as a site of origin for the STR.

In the present study we examined the sensitivity of the STR to pharmacological substances that are known to act as neuroactive agents on third order retinal neurons of the cat. We compared the effects of intravitreally injected drugs on the STR, PII and $a$-wave. Glycine and strychnine showed selective and opposing effects on the STR. GABA and bicuculline also showed opposing effects on the STR. The antagonizing effect of bicuculline could only be demonstrated in the presence of haloperidol. By comparison, the effects of other putative neurotransmitters used in this study were much less selective. We suggest that the retinal pathway that carries the rod-driven STR may be influenced by cells that use glycine or GABA as a transmitter.

\section{METHODS}

Light source, calibrations and recording system

The light stimulus was a tungsten-halogen filament lamp ( $2800 \mathrm{~K}$ color temperature) which diffusely illuminated a 16-in Ganzfeld sphere. The Ganzfeld luminance was measured in phot. ft $\mathrm{L}$ with a spot photometer (UDT $40 \mathrm{X}$-meter, Santa Monica, California), and the equivalent number of quanta per square visual degree (q/ $\mathrm{deg}^{2}$ ) at the cornea for an equivalent $507 \mathrm{~nm}$ source was calculated (Wyszecki \& Stiles, 1967 , p. 227). With the pupil of the animal fully dilated to $13 \mathrm{~mm}$ diameter, the unattenuated light had an intensity of $10.3 \log \mathrm{q} / \mathrm{deg}^{2} \mathrm{sec}$ [1 scot. td $=5.649 \log (507) / \mathrm{deg}^{2}$ sec]. Stimulus luminance was controlled by inserting neutral density filters in the light path. In the experiments reported below, the light stimulus was always spectrally unfiltered (i.e. "white" $2800 \mathrm{~K}$ ) and most often presented for the duration of $50 \mathrm{msec}$.
A Burian-Allen type, bipolar contact lens electrode (Hansen Ophthalmic Development Laboratories, lowa City) was used to record corneal ERGs. Signals were amplified by a total gain of 8000 with frequency range of $0.1-100 \mathrm{~Hz}$ and a $60 \mathrm{~Hz}$ notch filter. Responses were then digitized to 12 bits at a $1 \mathrm{msec}$ sampling rate.

An artifact rejection window was implemented in software, and responses were averaged. Individual responses were monitored with an oscilloscope. Usually, we averaged $30 \mathrm{re}$ sponses at the lowest intensity level but reduced this number to three responses at the higher levels. The data were saved on disk and displayed on a digital plotter.

\section{Animals}

All experiments were performed in the optically intact eye of adult cats using protocols approved by the Unit of Laboratory Animal Medicine at the University of Michigan. Animals weighed $2.5-4 \mathrm{~kg}$. They were sedated with xylazine ( $1 \mathrm{mg} / \mathrm{kg}$ i.m.) and atropine sulfate $(0.04 \mathrm{mg} / \mathrm{kg}$ i.m. $)$, then anesthetized with ketamine $\mathrm{HCl}$ (loading dose $10 \mathrm{mg} / \mathrm{kg} \mathrm{i} . \mathrm{m}$. and $6 \mathrm{mg} / \mathrm{kg} / \mathrm{hr}$ ). Pupils were dilated fully with atropine $1 \%$ eye drops. Corneas were kept moist with physiological saline.

\section{Pharmacological agents}

Table 1 shows the pharmacological agents and the concentrations at which they were tested in the experiments reported below. All drugs were dissolved in distilled water and adjusted to pH 7 with $\mathrm{NaOH}$ before administration. A single drug was always delivered in a volume of $0.05 \mathrm{~cm}^{3}$ to the vitreous through a 30 gauge

Table 1

\begin{tabular}{lcc}
\hline & $\begin{array}{c}\text { Estimated } \\
\text { Dose } \\
\text { Agent }\end{array}$ & $\begin{array}{c} \\
\text { ancentration } \\
\text { at the retina } \\
(\mathrm{mM})\end{array}$ \\
\hline GABA & 20.0 & 10.0 \\
Glycine & 20.0 & 10.0 \\
Dopamine & 10.0 & 5.0 \\
Serotonin & 5.0 & 2.5 \\
Acetylcholine & 10.0 & 5.0 \\
Strychnine (glycine antag.) & 0.2 & 0.1 \\
Bicuculline (GABA- $a$ antag.) & 0.2 & 0.1 \\
Picrotoxin (GABA-a antag.) & 0.15 & 0.075 \\
Phaclofen (GABA- $b$ antag.) & 1.0 & 0.5 \\
$\delta$-AVA (GABA- $b$ antag.) & 2.0 & 1.0 \\
Muscimol (GABA- $a$ agon.) & 10.0 & 5.0 \\
Baclofen (GABA-b agon.) & 5.0 & 2.5 \\
Haloperidol (dopa antag.) & 0.2 & 0.1 \\
\hline
\end{tabular}

All drugs were obtained from Sigma Chemical Co., except baclofen and phaclofen (Research Biochemical Inc.) 
needle inserted $6 \mathrm{~mm}$ posterior to the limbus. Injection of physiological saline $(0.9 \mathrm{~N} \mathrm{NaCl})$ or distilled water as a control had no effect on the ERG. In this paper, drug concentrations are expressed in total dose delivered, hence, in $\mu \mathrm{mol}$ per $0.05 \mathrm{ml}$ injection. The upper value of the actual drug concentration in the vitreous was estimated by dividing the quantity of drug injected by the approximate vitreal volume $(2 \mathrm{ml})$. Concentrations for drug effects were determined in preliminary experiments. A dose producing only small alterations of PII provided a lower limit. High doses caused retinal toxicity, and ERG responses became noisy. When agonist/antagonist effects were studied, the agonist was given 10-15 min after pretreatment with the antagonist. No retinal detachment or vitreous hemorrhage occurred in any case.

\section{Procedure}

Data collection was begun after $1 \frac{1}{2} \mathrm{hr}$ of dark adaptation. During the first part of every session, a $V-\log I$ curve of ERG responses was obtained as control values. An intravitreal injection was then given in dim red light immediately afterward, and ERGs were recorded again $1 \frac{1}{2} \mathrm{hr}$ later.

Figure 1 shows typical ERGs elicited from the normal dark adapted eye over a 7 log unit range of light intensities with $50 \mathrm{msec}$ stimuli. An $a$-wave is seen at high intensities, whereas the STR is found only at low intensities, near visual threshold (for the separation of the $a$-wave from the STR, see Sieving \& Nino, 1988; Wakabayashi et al., 1988). Only the STR is evident with the dimmest flashes (3.3-6.0 $\left.\log \mathrm{q} / \mathrm{deg}^{2} \mathrm{sec}\right)$. Since short stimuli help to separate the STR from PII, we typically used $50 \mathrm{msec}$ flashes.

At a criterion level of $3 \mu \mathrm{V}$, the threshold for the STR is usually around 3.3-3.6 log q/ $\mathrm{deg}^{2} \mathrm{sec}$ and PII-threshold near 5.3-5.6 log q/ $\mathrm{deg}^{2} \mathrm{sec}$ for $50 \mathrm{msec}$ flashes. Above this intensity PII becomes the major ERG component. With the brightest flashes, the $a$-wave precedes PII. Since the $a$-wave amplitude, latency (time to onset) and implicit time (time to peak) were not affected by any of the drugs at the concentrations we used, we do not show further ERG traces obtained at the highest illuminance levels.
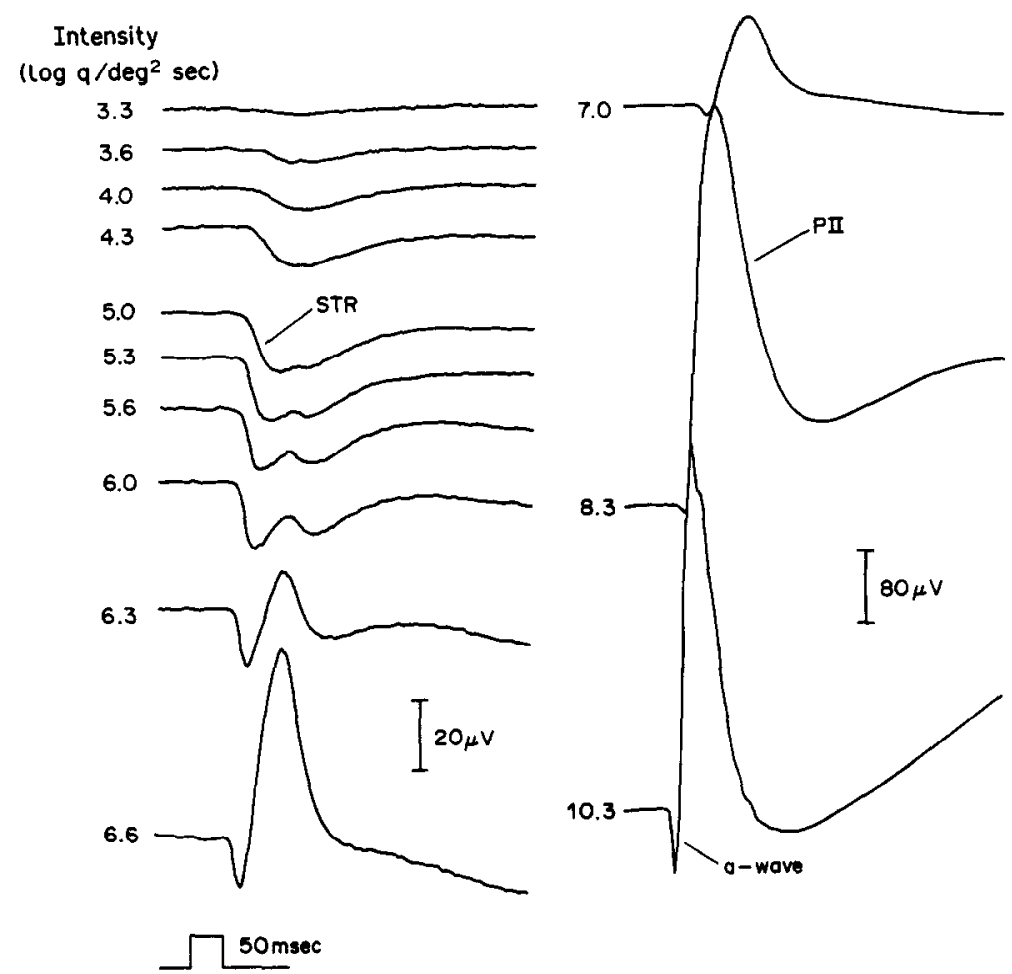

Fig. 1. Corneal ERG responses elicited from the normal dark adapted cat eye to $50 \mathrm{msec}$ "white light" stimuli over the intensity range of $3.3-10.3 \mathrm{log} \mathrm{q} / \mathrm{deg}^{2} \mathrm{sec}$ as indicated in the left column. Only the STR is evident with dim flashes. PII-threshold is near $5.0 \log \mathrm{q} / \mathrm{deg}^{2} \mathrm{sec}$, with PII amplitude as the dominant component present at moderate intensities. The $a$-wave precedes PII with the brightest flashes. Maximum amplitudes: STR $=20 \mu \mathrm{V}, \mathrm{PII}=480 \mu \mathrm{V}$ and $a$-wave $=70 \mu \mathrm{V}$. Note the change of scale for intensities higher than $6.6 \log \mathrm{q} / \mathrm{deg}^{2} \mathrm{sec}$. 
Amplitude of the STR was measured from baseline to trough, and PII amplitude from STR-trough to peak or from $a$-wave-trough to peak. Maximum STR amplitudes occur usually in the range of $15-35 \mu \mathrm{V}$, maximum PII amplitudes in the range of $400-800 \mu \mathrm{V}$.

Experimental sessions lasted from 3 to $8 \mathrm{hr}$. PII amplitude was recorded from the nonexperimental "fellow" eye and used as a critical indicator of the stability of the animal's condition. Most experiments were performed on acute animals. In some cases (including the experiments represented by Figs 2 and 4), the animal was recovered from anesthesia following completion of a session, and the ERG was reexamined several days later.

Data from a total of 70 acute animals were used. Each finding was replicated in at least three animals. With the exception of $\delta$-AVA effects on PII, all drug effects showed good consistency once the effective dosages had been established.

\section{RESULTS}

\section{Glycine effects}

The inner retina of the cat contains some bipolar cells and at least four different morphological subclasses of amacrine cells that accumulate glycine (Pourcho, 1980), although not all of these cells necessarily use glycine as a neurotransmitter (Massey \& Redburn, 1987). Some glycinergic amacrine cells make reciprocal synapses with bipolar terminals and also contact other amacrine cells, in addition to ganglion cells (Kolb \& Nelson, 1984). We administered $20 \mu \mathrm{mol}$ glycine intravitreally, with the results shown in Fig. 2a. Compared with control responses (left panel), glycine suppressed the STR quite effectively (second panel from left) but did not alter PII threshold even though the amplitude of $\mathrm{PII}_{\max }$ was somewhat reduced. The $a$-wave (not shown here, at $8 \log \mathrm{q} / \mathrm{deg}^{2} \mathrm{sec}$ and higher) was not affected by glycine.

This cat was recovered for 3 days with no intervention on our part, and subsequent ERG recordings (third panel) showed full recovery of both the STR and PII responses and reversibility of the glycine induced effects. On recovery from glycine (and GABA, described below), the STR amplitude was typically enhanced. Glycine was again applied, resulting in strong suppression of the STR (fourth panel).

Figure $2 \mathrm{~b}$ and $\mathrm{c}$ show $V-\log I$ curves for the STR and PII, recorded in the absence and presence of glycine. After glycine (Fig. 2b) the tiny STR amplitude did not increase with stimulus intensities above $4.3 \log \mathrm{q} / \mathrm{deg}^{2} \mathrm{sec}$. However, as seen in Fig. 2a, the latency of this wavelet shortened with increased intensity and was the same as the control STR, which suggests that this response is likely to be a residue of the STR. The curve of PII (Fig. 2c) shows that $V_{\text {max }}$ is reduced by about one-third but with no change in the semi-saturation constant.

The effects of glycine appear to be mediated by conventional glycine receptors since we could block the effect by strychnine. In the presence of glycine plus strychnine, STR amplitudes were even enhanced slightly but reliably (Fig. 3a). Strychnine also effectively blocked glycine effects on PII (Fig. 3) and $V_{\max }$ was reduced by only $10 \%$, which is less than for glycine alone.

\section{$G A B A$ effects}

The action of GABA on most amacrine and ganglion cells in mudpuppy (Miller, Frumkes, Slaughter \& Dacheux, 1981) and cat (Bolz, Frumkes, Voigt \& Wassle, 1985a; Bolz, Thier, Voigt \& Wassle, 1985b) is very similar to glycinc. Therefore, if indeed proximal in origin, the STR is also likely to be suppressed by GABA, given the prominence of GABA-ergic amacrine cells (Pourcho \& Goebel, 1983) and their extensive physiological influence (Bolz et al., 1985a; Straschill \& Perwein, 1969). Figure 4a shows ERG responses before (left panel) and after (middle panel) treatment with $20 \mu$ mol intravitreal GABA. GABA eliminated the STR and sensitized PII, that is, PII threshold was lowered slightly by $0.5 \log$ units, and its amplitude increased. The $a$-wave (not shown) was not affected by GABA.

ERG responses were recorded again from this eye 3 days later (right panel), and they showed reversibility of all GABA-induced effects. In fact, on recovery, the STR responses were larger than those obtained initially in the control record. $V-\log I$ plots for these STR and PII responses are shown in Fig. $4 b$ and $c$, with additional data not shown in Fig. 4a. The STR curve showed the profound suppression by GABA. Over its entire dynamic range, PII amplitude was enhanced by GABA, and the semi-saturation constant was shifted to the left by 0.5 log units (Fig. 4c).

The synaptic action of GABA at GABA- $a$ receptor sites is inhibitory by modulation of a chloride conductance (Miller et al., 1981). The two common GABA- $a$ antagonists affect this 
(a)

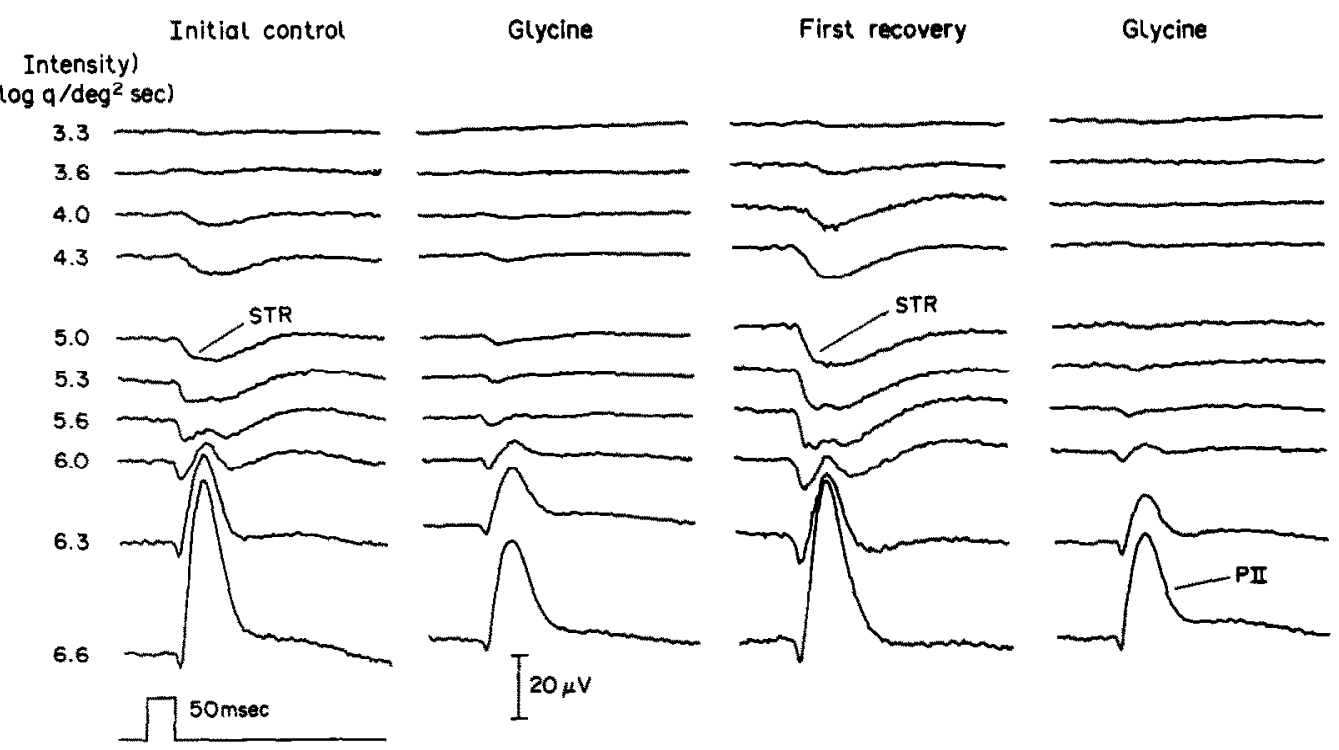

(b)

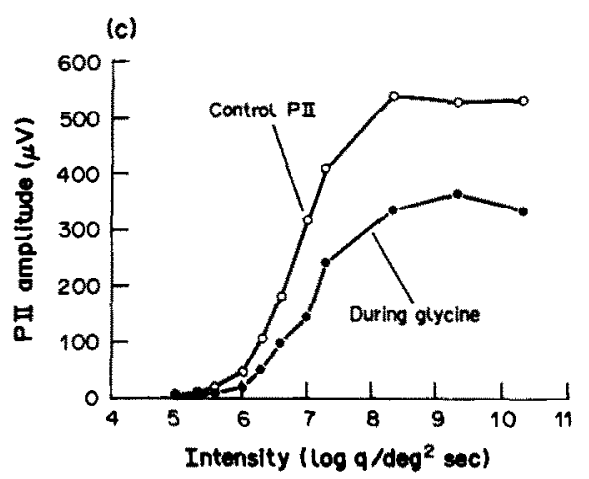

Fig. 2. Effects of $20 \mu \mathrm{mol}$ glycine on ERG responses. (a) Comparison of ERG responses before (left panel) and after (middle panel) treatment with intravitreal glycine on the first day (two left panels) and again after recovery 3 days later (two right panels). Responses recorded 3 days later (right panel) show reversibility of glycine effects. The $a$-wave (not shown) was not affected by glycine. (b) $V-\log I$ plot for STR in the control condition and following glycine treatment. STR data are from (a). (c) $V-\log I$ plot for PII in control and experimental condition. PII data were obtained over the intensity range $5.3-10.3 \log q / \mathrm{deg}^{2} \mathrm{sec}$.

(a)

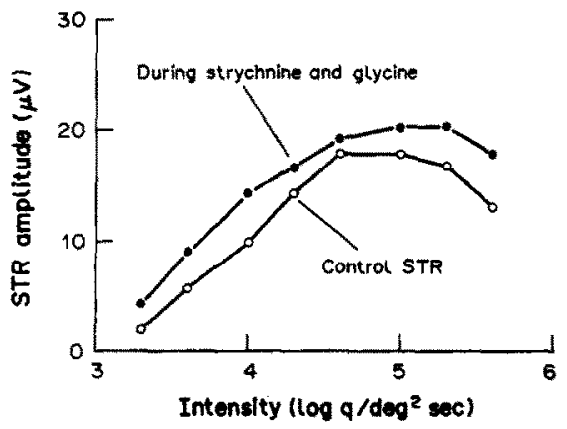

(b)

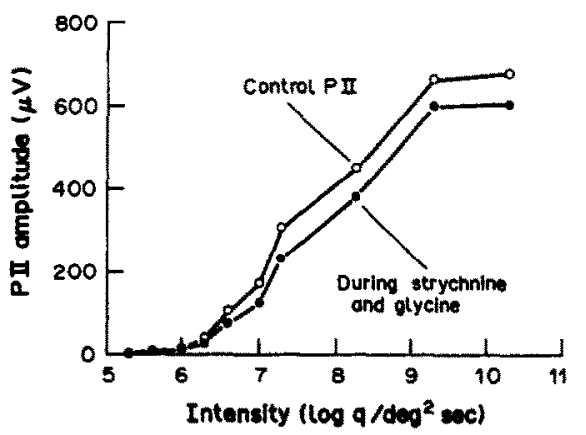

Fig. 3. $V-\log I$ plots for STR (a) and PII (b) showing the effects of glycine $(20 \mu \mathrm{mol})$ in the presence of glycine-antagonist, strychnine $(0.15 \mu \mathrm{mol})$. 


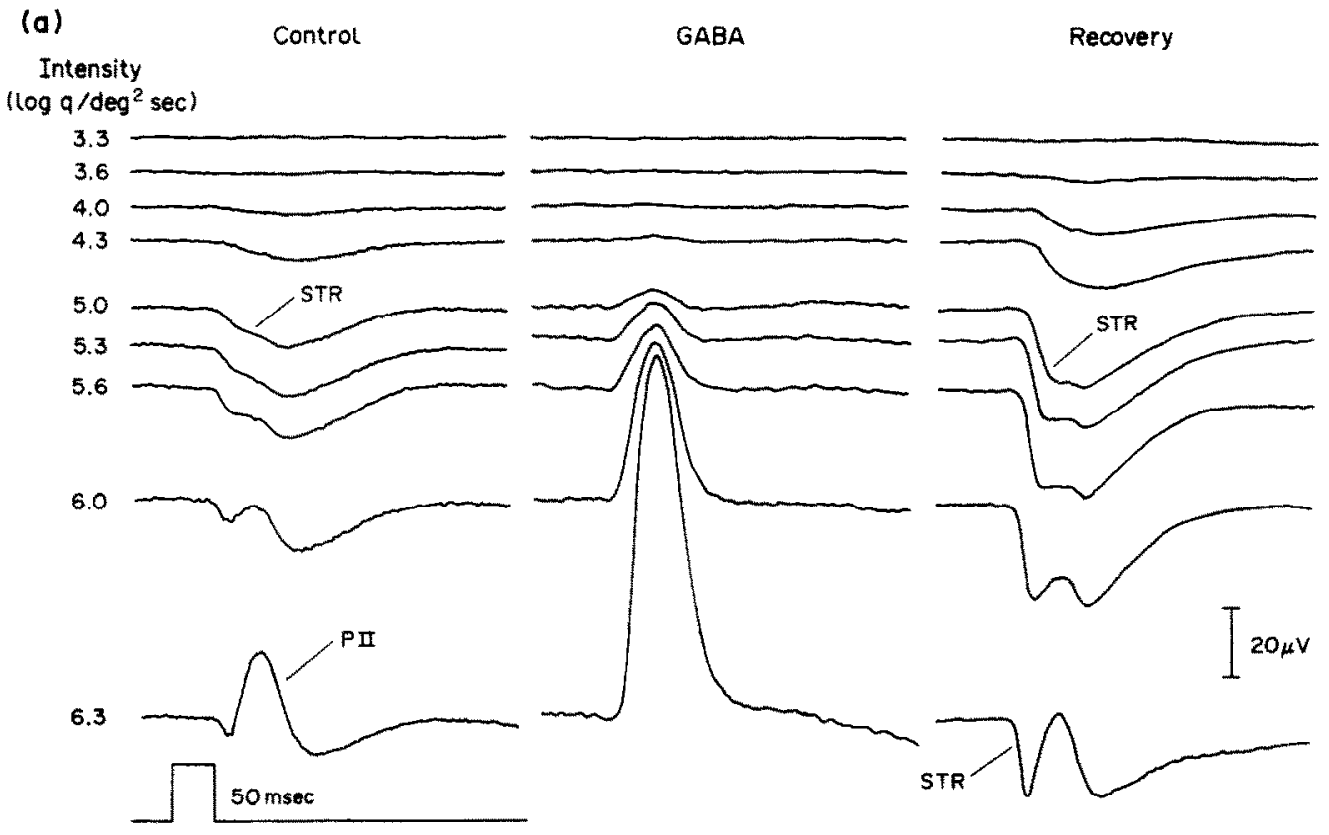

(b)

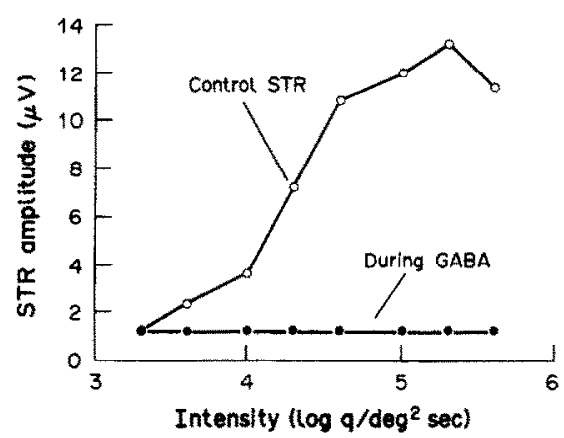

(c)

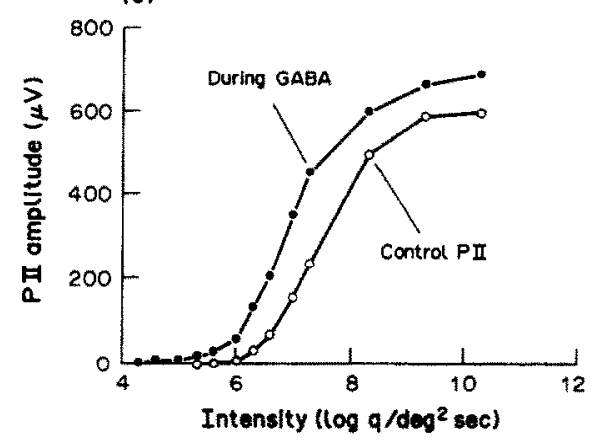

Fig. 4. Effects of $20 \mu \mathrm{mol}$ GABA on corneal ERG responses. (a) Comparison of ERG responses before (left panel) and during (middle panel) treatment with $20 \mu \mathrm{mol}$ intravitreal GABA. Responses recorded 3 days later (right panel) showed reversibility of GABA induced effects. The $a$-wave (not shown) was not affected by GABA. (b) $V-\log I$ plot for STR in the control condition and following GABA treatment. STR data are from (a). (c) $V-\log I$ plot for PII in the control and experimental condition. PII data were obtained over the intensity range $5.3-10.3 \log \mathrm{q} / \mathrm{deg}^{2} \mathrm{sec}$.

receptor-complex in different ways. Bicuculline is an antagonist at the GABA recognition site. Picrotoxin is also a GABA- $a$ antagonist, but it blocks the ability of receptor-bound GABA to open chloride channels (cf. Bormann, 1988). The effects on $V-\log I$ plots of the ERG of these antagonists followed by $20 \mu \mathrm{mol}$ GABA are shown in Fig. 5a for the STR. The open symbols represent control data. The solid circles represent pretreatment with $0.2 \mu \mathrm{mol}$ bicuculline, and the open squares show pretreatment with $0.17 \mu \mathrm{mol}$ picrotoxin, followed by GABA in each case. Both antagonists only partially blocked the suppression of the STR by GABA. Recall that GABA alone completely suppressed the STR (Fig. 4). The enhancement of PII by
GABA (Fig. 4) was apparently completely blocked by bicuculline (Fig. 5b). Picrotoxin, however, partially suppressed PII.

These results with GABA- $a$ antagonists made us wonder whether GABA also had some other action on the ERG. Recent evidence (e.g. Dutar \& Nicoll, 1988) suggests that there may be another type of GABA receptor, i.e. GABA- $b$, which is insensitive to bicuculline (cf. Bormann, 1988). GABA- $b$ may be coupled to $\mathrm{Ca}^{2+}$ and/or $\mathrm{K}^{+}$channels via the activation of guanine nucleotide binding proteins in the cell membrane (Bormann, 1988). To determine whether GABA-b receptors were mediating the suppression of the STR, we administered either phaclofen (GABA- $b$ antagonist) or $\delta$-amino 
(a)

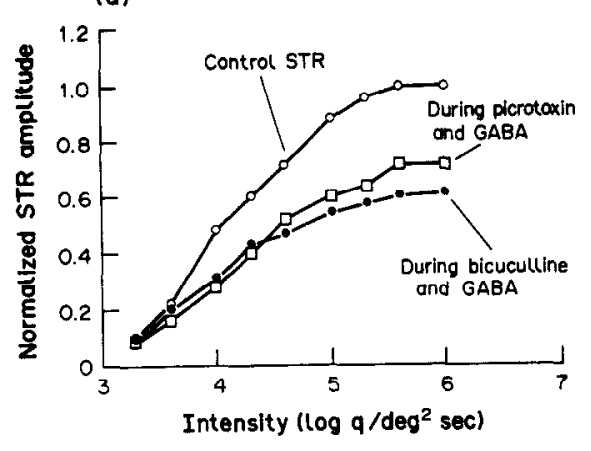

(b)

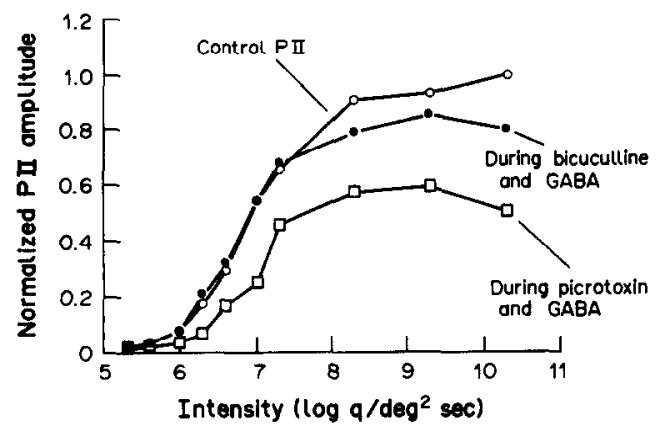

Fig. 5. V-log $I$ plots for STR (a) and PII (b) showing the effects of GABA $(20 \mu \mathrm{mol})$ in the presence of either bicuculline $(0.2 \mu \mathrm{mol})$ or picrotoxin $(0.17 \mu \mathrm{mol})$. All amplitudes are normalized.

valeric acid ( $\delta$-AVA: GABA- $a$ agonist/GABA- $b$ antagonist; see McGuire, Lukasiewicz \& Werblin, 1989) to fresh eyes before GABA application. Figure 6a shows that neither of these substances blocked the suppression of the STR by GABA. However, phaclofen (Fig. 6b) seemed to block the effects of GABA on PII; $\delta$-AVA sometimes suppressed the amplitude of PII but at other times had no effect.

Since neither GABA- $a$ nor GABA- $b$ antagonists completely blocked the effects on the STR, we were not able to identify clearly in this stage of our study the receptor type which presumably mediates these GABA results. Subsequently, we identified an interaction of GABA- $a$ antagonists with endogeneous dopamine, which clarified our results and ultimately lead us to conclude that GABA- $a$ receptors mediated the GABA effects on the STR. We will temporarily defer considering this interaction with endogeneous dopamine until later in this paper.

\section{Effects of serotonin, acetylcholine and dopamine}

We also studied three other neuroactive agents known to be present in the inner retina of the cat-serotonin (Holmgren-Taylor, 1983), acetylcholine (Pourcho \& Osman, 1985) and dopamine (Pourcho, 1982; Oyster, Takahashi, Cilluffo \& Brecha 1985)-and compared their effects to those of glycine and GABA.

Figure 7 shows that serotonin suppressed the STR amplitude by about $50 \%$ and suppressed PII amplitude even more: near its threshold and across the entire intensity range. Other dosages of serotonin were no more selective for the STR vs PII.

Similarly, neither acetylcholine nor dopamine produced a selective suppression or enhancement of either the STR or PII (traces not shown).

Figure 8 summarizes the results for the five neuroactive agonists, by the percent change from $V_{\max }$ of STR and of PII. Glycine and GABA each affected the STR most selectively over against PII amplitude. Acetylcholine and serotonin were much less effective in suppressing the STR and were considerably less selective for STR vs PII than GABA or glycine. Dopamine heavily suppressed both the STR and PII and was clearly nonselective. With smaller dosages, dopamine still did not match the differential selectivity of glycine or GABA.
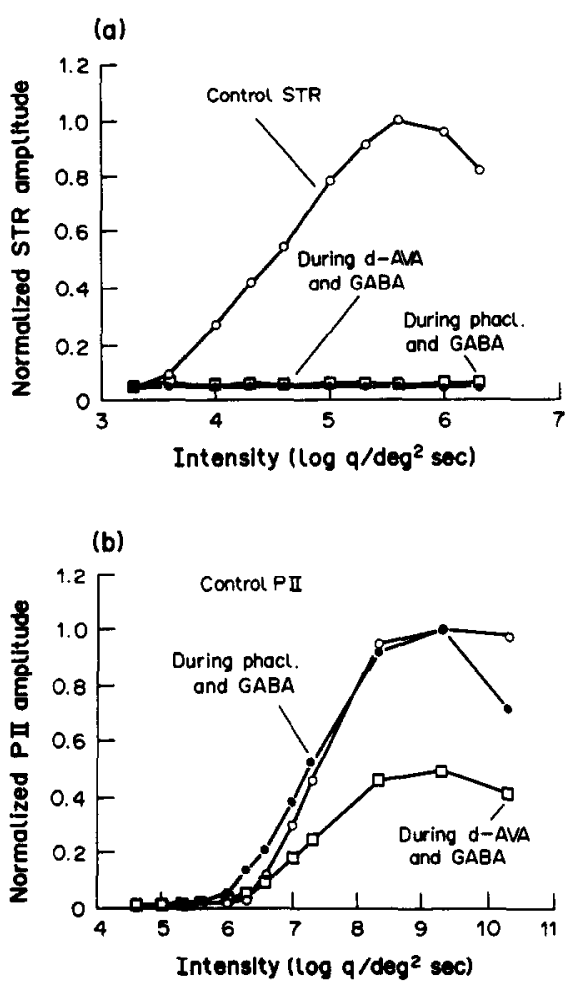

Fig. 6. $V-\log I$ plots for STR (a) and PII (b) showing the effects of GABA $(20 \mu \mathrm{mol})$ in the presence of either phaclofen $(0.5 \mu \mathrm{mol})$ or $\delta$-AVA. All amplitudes are normalized. 


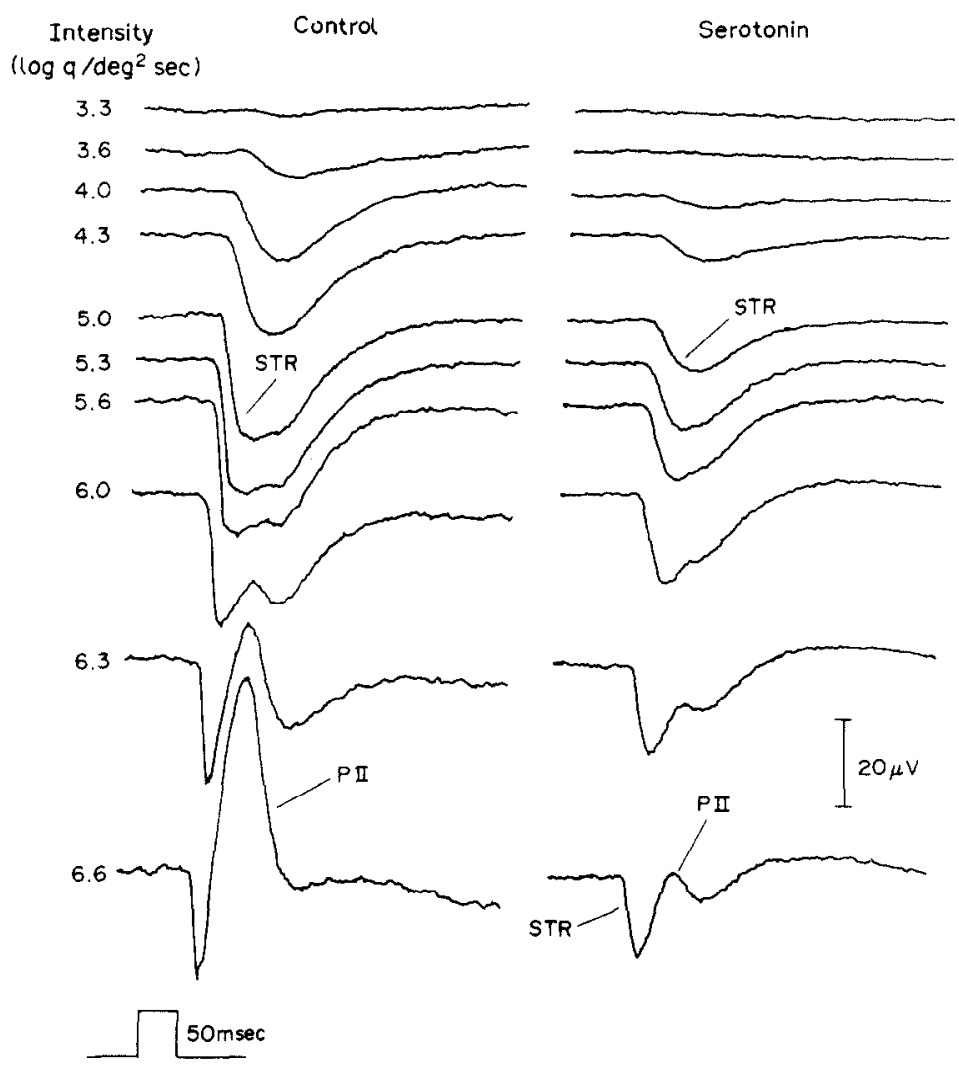

Fig. 7. Influence of $10 \mu \mathrm{mol}$ intravitreal serotonin on ERG responses. The panel on the left shows control responses; PII threshold is around 5.3-5.6 log q/ $\mathrm{deg}^{2} \mathrm{sec}$. Serotonin affects STR-amplitudes, but does not eliminate the response. PII amplitude is reduced by about $75 \%$ at $6.6 \log \mathrm{q} / \mathrm{deg}^{2} \mathrm{sec}$.

\section{Effects of glycine- and GABA-antagonists}

After finding that exogeneously applied GABA and glycine were much more specific for the STR than were acetylcholine, serotonin or dopamine, we assessed the role of endogeneous glycine and GABA. Figure 9 shows the effect of bicuculline and of strychnine on $V-\log I$ curves of STR and PII. Strychnine increased the STR amplitude over its entire dynamic range

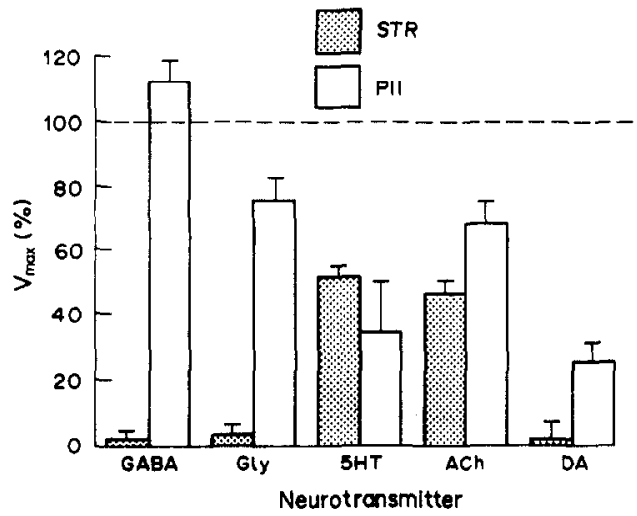

Fig. 8. Percent change in $V_{\max }$ of PII and STR induced by each neurotransmitter analogue used. The vertical hashmarks indicate the standard error of the mean.
(Fig. 9a). PII amplitude was affected minimally or was reduced slightly (Fig. 9b), while the $a$-wave was not affected (not shown). This effect of strychnine on the STR was opposite to that of glycine alone (Fig. 2) and suggests that endogeneous glycine influences the cells that generate the STR.

Doses of bicuculline that caused minimal reduction of PII also reduced the STR, thus acting in the same direction as GABA alone (Fig. 4). Although not shown here, picrotoxin also suppressed the STR to the same extent as bicuculline, but it suppressed PII to an even greater extent.

Interaction of GABA-a antagonists and endogeneous dopamine

Since bicuculline and picrotoxin differ in mode of action at the postsynaptic site, we tested whether simultaneous application of the two might be more effective. Figure 10a (right panel) shows that the STR was totally suppressed by this combination and that PII amplitude was very much diminished. However, a slow negative wave remained at about $2.5 \mathrm{log}$ unit above absolute threshold 
(a)

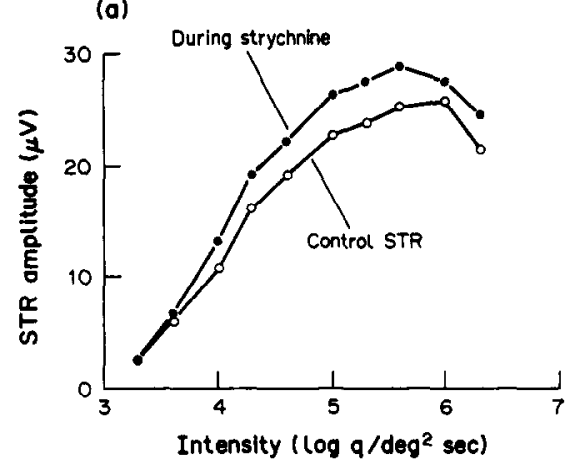

(c)

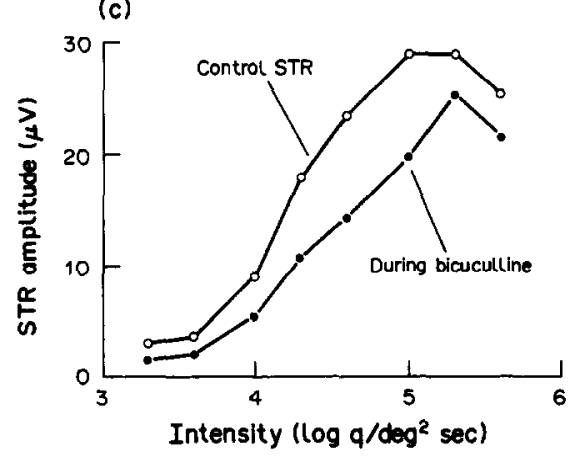

(b)

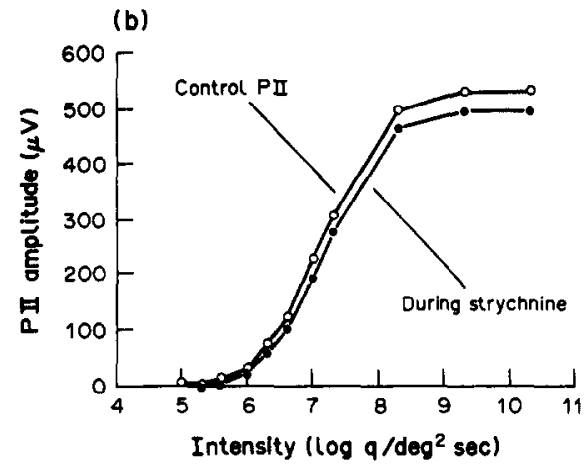

(d)

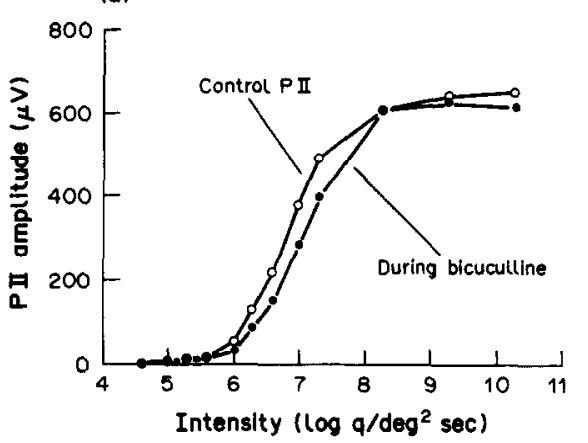

Fig. 9. $V-\log I$ plots for STR and PII showing the effects of $0.15 \mu \mathrm{mol}$ strychnine (a and b) and of $0.2 \mu \mathrm{mol}$ bicuculline (c and d).

(i.e. $6.0 \log \mathrm{q} / \mathrm{deg}^{2} \mathrm{sec}$ ). Although this had the polarity of an STR, the latency (time to onset) was nearly $50 \mathrm{msec}$ longer than expected for the STR for $50 \mathrm{msec}$ duration stimulus. Previously, we had observed a similar negative wave with delayed latency at these intensities while investigating the influence of dopamine, and we show the effects of dopamine in Fig. 10a (middle panel) for comparison.

To determine whether this wave might be a response to stimulus cessation, we used a stimulus of $200 \mathrm{msec}$ duration which, at its cessation, elicits a characteristic off-component in PII but does not shift the latency of the STR. The results are shown in Fig. 10b. The STR waveforms are similar and have the same latencies for 50 and $200 \mathrm{msec}$ flashes at $4.3 \log \mathrm{q} / \mathrm{deg}^{2} \mathrm{sec}$ (control 1). Just above PII threshold, at $5.6 \log \mathrm{q} / \mathrm{deg}^{2} \mathrm{sec}$ (control 2), the $200 \mathrm{msec}$ flash elicits a distinct PII-off component after the normal STR. With dopamine or picrotoxin/bicuculline, the waveform is predominantly negative but is delayed beyond the normal latency of the STR, and $200 \mathrm{msec}$ flashes suggest that this activity may be PII-off rather than an STR.

Based on the similarity of waveforms in Fig. 10(a,b), we suspected that endogeneous dopamine had a role in the anomalous effects that we found for bicuculline and/or picrotoxin. Indeed, previous reports have suggested that GABA- $a$ antagonists can release dopamine from the retina of rat (Kamp \& Morgan, 1981) and carp (Negishi, Teranishi \& Kato, 1983; O'Connor, Dorison, Watling \& Dowling, 1986). We injected haloperidol $(0.1 \mu \mathrm{mol})$ in the vitreous, with the effects shown in Fig. 11a and $b$. Over the illuminance range of 3.3-5.0 $\log \mathrm{q} / \mathrm{deg}^{2} \mathrm{sec}$, haloperidol did not affect the STR (Fig. 11a). However, above $5.0 \log \mathrm{q} / \mathrm{deg}^{2} \mathrm{sec}$ haloperidol enhanced both the STR and PII. This suggests that endogeneous dopamine affects ERG waves at intensities of at least 2 log units above absolute threshold. Figure $11 \mathrm{c}$ and $\mathrm{d}$ shows the effects of bicuculline $(0.2 \mu \mathrm{mol})$ in the presence of haloperidol $(0.2 \mu \mathrm{mol})$. Both the STR and PII were enhanced at all intensities. Based on the results shown in Fig. 11a, the enhancement of the STR at intensities below $5.3 \log \mathrm{q} / \mathrm{deg}^{2} \mathrm{sec}$ (Fig. 11c), was most likely due to the action of bicuculline.

With the bicuculline/haloperidol combination, we were able to block completely the suppression of the STR by $20 \mu \mathrm{mol}$ GABA (Fig. 11e). However, PII was again enhanced. And, as the data in Figs 4 and $11(a, b)$ show, this 
(a)

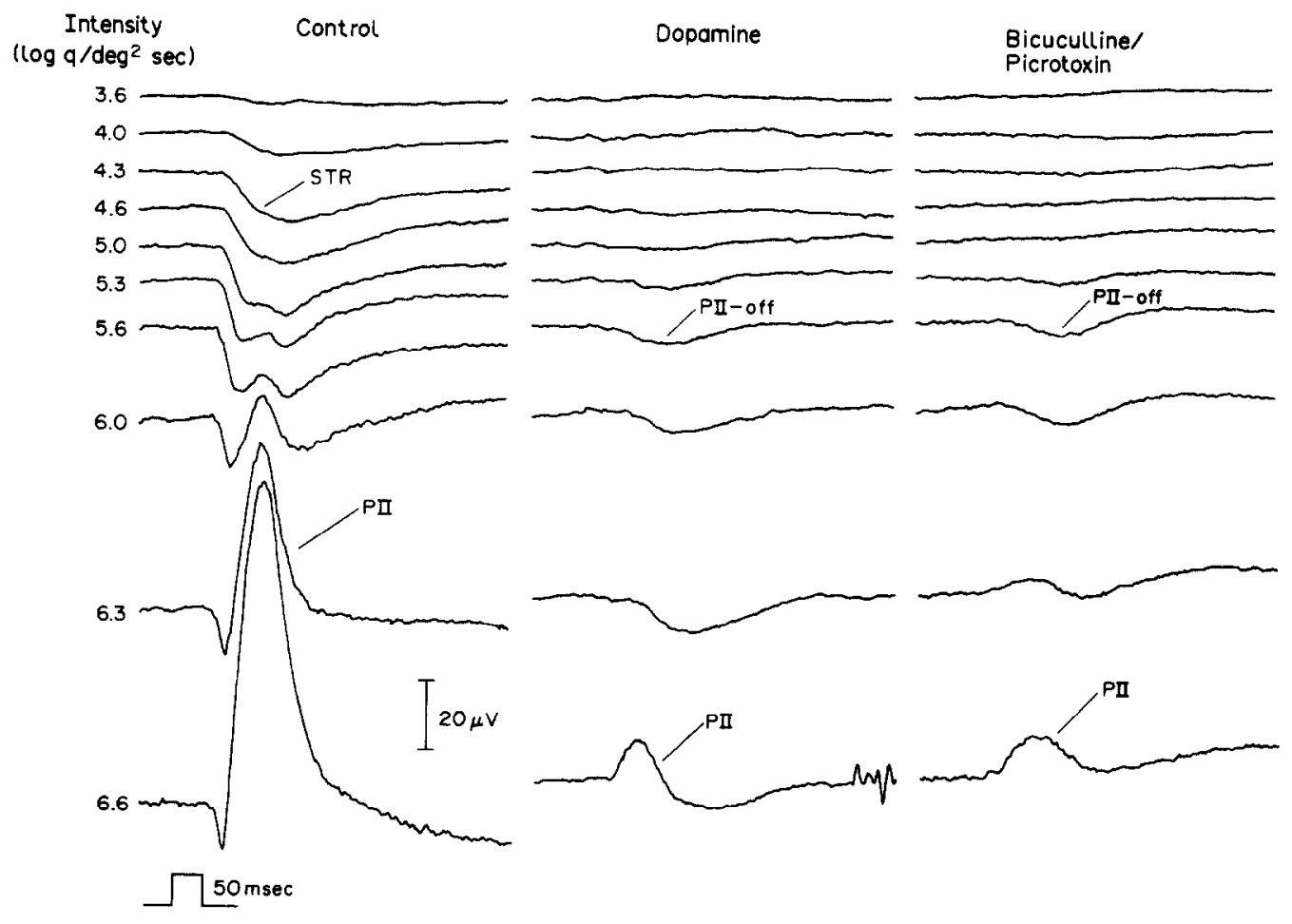

(b)

Intensity

$\left(\log q /\right.$ deg $\left.^{2} \mathrm{sec}\right)$

4.3

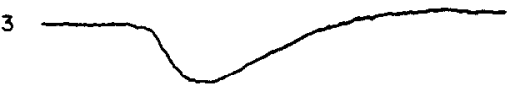

5.6

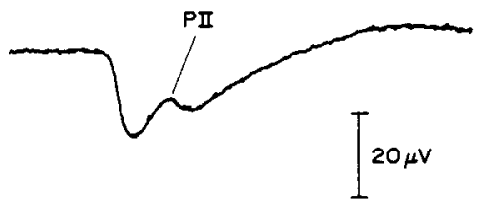

6.0

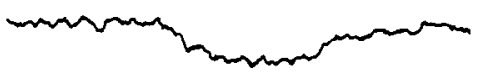

6.3

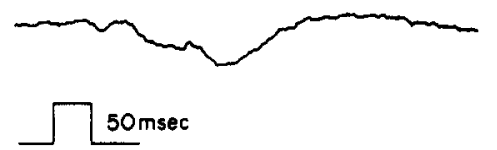

Control 1

Control 2

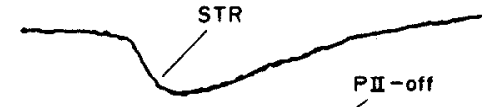

PII-of

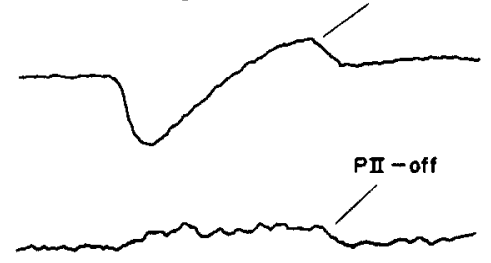

Bicu/Picro

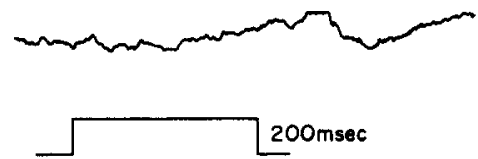

Fig. 10. Comparison of the effects of dopamine with the effects of a combination of picrotoxin and bicuculline on ERG responses. (a) ERG responses before (left panel) and during treatment with $1 \mu \mathrm{mol}$ dopamine (middle panel). The right panel shows the effect of $(0.2 \mu \mathrm{mol})$ bicuculline plus $(0.2 \mu \mathrm{mol})$ picrotoxin on responses obtained in a different eye. (b) ERG waves in response to a $50 \mathrm{msec}$ (left panel) and a $200 \mathrm{msec}$ (right panel) duration stimulus on STR and PII. The traces in the first and second row are control responses. The traces in the third and fourth row show the effects of dopamine $(1 \mu \mathrm{mol})$ and the effects a combination of picrotoxin $(0.1 \mu \mathrm{mol})$ plus bicuculline $(0.1 \mu \mathrm{mol})$, respectively.

enhancement might have been due to either GABA and/or haloperidol.

It had been shown that phaclofen (Fig. 6) could also block GABA-effects on PII. There- fore, we asked again which receptors were mediating GABA effects on PII by administering GABA- $b$ and GABA- $a$ agonists. Figure 12 (right panel) shows that baclofen (GABA-b 
(a)

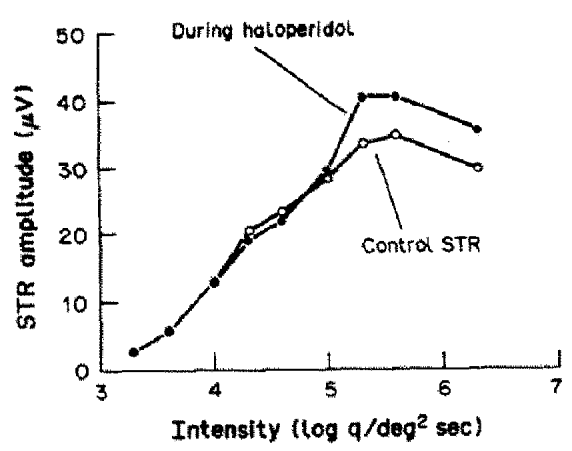

(c)

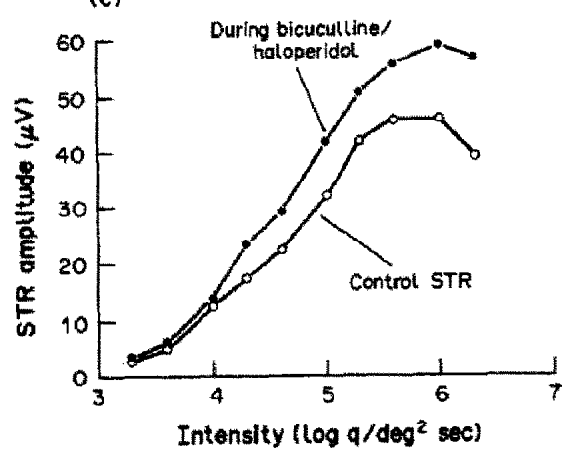

(e)

Control
$\left(\log \mathrm{q} / \mathrm{deg}^{2} \mathrm{sec}\right)$
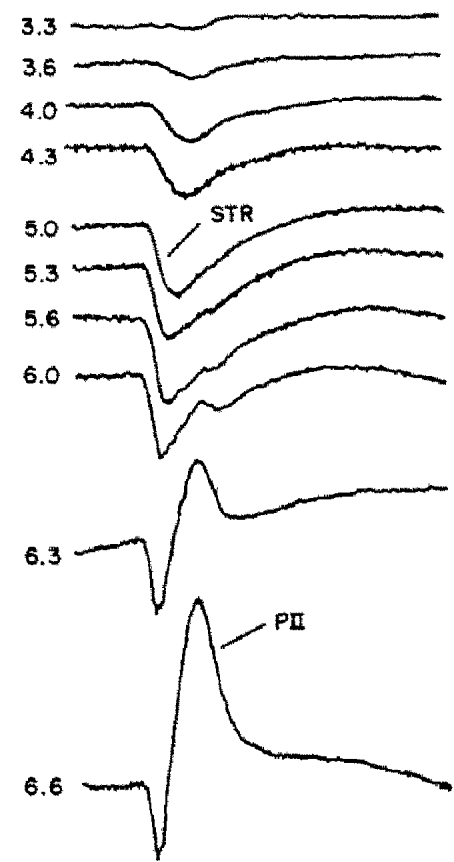

50 mesc (b)

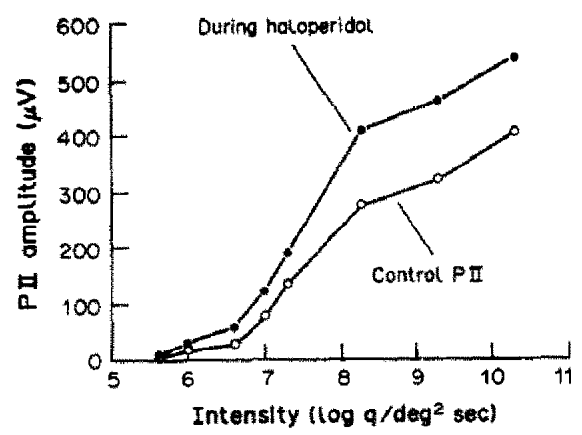

(d)

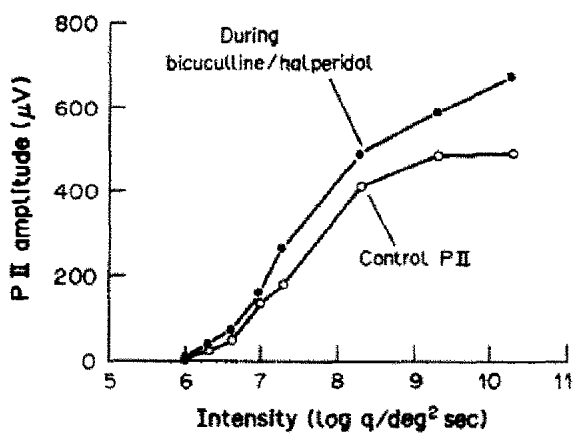

Haldol / bicuculline

and

GABA

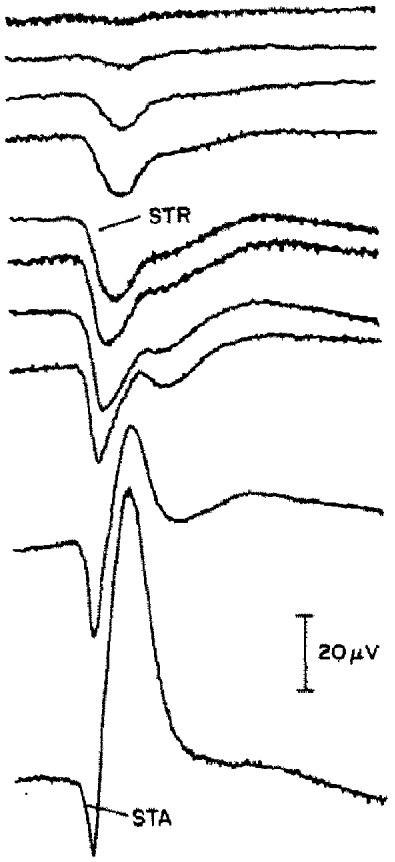

Fig. 11. $V-\log /$ plots for STR and PII showing the effects of $0.2 \mu \mathrm{mol}$ haloperidol (a and b) and effects of a combination of $0.2 \mu \mathrm{mol}$ bicuculine and $0.2 \mu \mathrm{mol}$ haloperidol (c and d). The traces in (e) show the effects of $20 \mu \mathrm{mol}$ GABA on the ERG in the presence of a combination of bicuculline $(0.2 \mu \mathrm{mol})$ plus haloperidol $(0.2 \mu \mathrm{mol})$. 


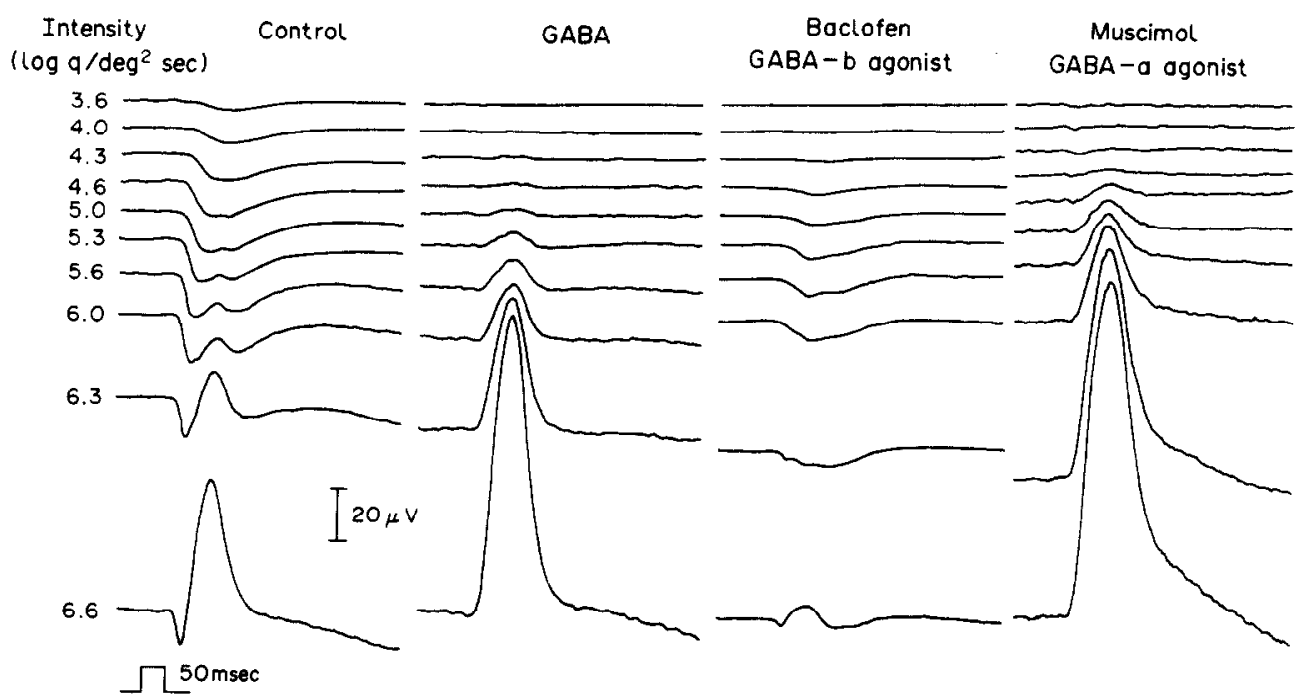

Fig. 12. Comparison of the effects of GABA $(20 \mu \mathrm{mol})$, muscimol $(10 \mu \mathrm{mol})$ and baclofen $(10 \mu \mathrm{mol})$ on STR and PII.

agonist) suppressed PII amplitude and reduced but did not eliminate the STR. On the other hand, muscimol (GABA- $a$ agonist) enhanced PII amplitude and also suppressed the STR (Fig. 12, middle panel) comparable to GABA alone. These data suggest that GABA- $a$ and not GABA- $b$ receptors were mediating the enhancing effects of GABA on PII. Moreover, they provide additional evidence that the effects of GABA on the STR were mediated by GABA- $a$ receptors, which is consistent with results shown in Fig. 11c and $11 \mathrm{e}$.

\section{DISCUSSION}

In this study we found that the STR can be modulated independently of PII by pharmacological agents known to have their active sites primarily in the inner retina of the cat. Exogeneously applied glycine and GABA selectively suppressed the STR with relatively small effect on or even enhancement of PII and no effect on the $a$-wave. Thus, our results suggest that the STR may arise from a source which is distinctly different from those that produce PII or the $a$-wave. Acetylcholine, dopamine and serotonin did not show selectivity for the STR.

Other studies have also reported on glycine and GABA effects on PII of several species but not on the STR. There is reasonable agreement that glycine has little or no suppressive effect on PII (see Stockton \& Slaughter, 1989; Wachtmeister \& Dowling, 1978). However, a consensus is lacking regarding GABA effects on PII, since GABA has been reported to enhance
(Starr, 1975; Dick \& Miller, 1985a, b), reduce (De Vries \& Friedman, 1978; Gottlob, Wundsch \& Tuppy, 1988; Bonaventure, Wioland \& Mandel, 1974) or not to alter (Wachtmeister, 1980; Yonemura, Kawasaki, Yanagida, Tanabe, Kawaguchi \& Nagata, 1979) PII amplitude. These conflicting results may derive not only from species differences but from the types of preparation and/or means of drug application used, as well as from the state of retinal adaptation. But in all of these reports, the magnitude of PII alteration by GABA is relatively small (by $\pm 10-30 \%$ ), compared to the almost complete suppression (by $90-100 \%$ ) of the STR that we report in this study. It seems then, that GABA and glycine permit a pharmacological separation of the STR from PII and from the $a$-wave.

Strychnine always enhanced the STR. This enhancement is of interest since it is known for some time (Miller, Dacheux \& Frumkes, 1977) that many on-off ganglion cells and also some amacrine cells show larger light responses after the application of strychnine or bicuculline. These larger light responses have been associated with an increase in input resistance of these cells. It has been suggested (Miller et al., 1977), therefore, that both glycine and GABA are released in the dark and that light evoked increases are superimposed on a continuous low level of transmitter release. Our finding of an enhancement of the STR by strychnine also suggests a continuous dark release of endogeneous glycine. This effect may reside proximal to PII since strychnine did not enhance PII. 
Two observations in our study suggest a dark release of GABA (see Fig. 11a,c). One observation is the absence of any influence of haloperidol alone on the STR below $5.0 \log q / \mathrm{deg}^{2} \mathrm{sec}$. Interestingly, haloperidol begins to affect the STR only at about $2 \log$ units above ERG threshold (or about 2.5-3 log units above absolute threshold). This would suggest that dopamine is not released in the dark but is released by light flashes of intensities higher than $5 \log \mathrm{q} / \mathrm{deg}^{2} \mathrm{sec}$ (see Fig. 11a). The action of dopamine seems to be rather unspecific, since haloperidol enhances the STR (at higher intensities) and PII. We also noted an enhanced $a$-wave (not shown) with haloperidol, as previously reported in monkey by Bodis-Wollner, Marx and Ghilardi (1987). The other observation is the enhancement of the STR by bicuculline in the presence of haloperidol. In fishes (O'Connor et al., 1986), GABA- $a$ antagonists facilitate the release of endogeneous dopamine. This release has been shown to be $\mathrm{Ca}^{2+}$ dependent, indicative of a synaptic mechanism. Haloperidol generally blocks the action of dopamine postsynaptically, and we are not aware of evidence in the literature that haloperidol interferes with the action of bicuculline per se. The action of bicuculline is presumably exerted at presynaptic sites of dopaminecontaining cells. Thus, in the presence of haloperidol, bicuculline may still act on postsynaptic GABA receptor sites and block GABA action. Our data suggest that the enhancement of the STR at low intensities in Fig. $11 \mathrm{~b}$ results from the antagonizing effects of bicuculline at the $\mathrm{GABA}$ receptor site as it blocked the action of GABA released in the dark.

Thus, our results with strychnine and GABA$a$ antagonists suggest that endogeneous glycine and GABA selectivity influence the cells that control the STR. These cells may be amacrine cells, since ganglion cells are known not to contribute to the STR (Sieving, 1991).

If indeed GABA and glycine act primarily by way of a shunting mechanism on neurons of the inner retina (Miller \& Dacheux, 1983), their action suggest the involvement of a depolarizing type of cell in the generation of the negativegoing STR. This interpretation of our result appears to be consistent with Frishman and Steinberg's proposal (1989) that the STR results from a Müller cell response to light-evoked $\mathrm{K}^{+}$ fluxes that originate in depolarizing amacrine cells and/or ganglion cells. We speculate, then, that the STR may originate in a class of rod driven depolarizing amacrine cells operating with a narrow intensity range near absolute threshold.

Reports describing the anatomical and physiological organization of the rod on- and off-pathway in the cat retina (Kolb \& Nelson, 1983, 1984; Famiglietti, 1983; Sterling, 1983) have established that some rod amacrine cells receive rod bipolar cell output almost exclusively and form (through cone bipolar cells) the only input to ganglion cells or feedback onto rod bipolar cells (Kolb \& Nelson, 1983). AII amacrine cells contact ganglion cells, and A17 cells feed back onto rod bipolar cells. Both cell types give a depolarizing on-response to a dim light stimulus: the AII cell responds with a phasic waveform, whereas the A17 cell with a more sustained waveform. According to Kolb and Nelson (1983), the wide-field morphology of the A17 cell may facilitate integration of rod information over a large retinal area and increase sensitivity levels at the inner plexiform layer. The narrow-field AII amacrine cell of the rod system may serve more to speed up rod signals (Nelson, 1982) for selective output to ganglion cells. Thus, a class of cells with the kind of connectivity, morphology and physiology similar to that of the A17 cell may very well underlie the STR.

Although, GABA and glycine act directly and primarily on third order neurons in the cat retina (Bolz et al., 1985a, b; Wassle, SchaferTrenkler \& Voigt, 1986) the inner retina is clearly not their only regional site of action. For example, the presence of GABA has also been demonstrated in interplexiform cells (Nakamura, McGuire \& Sterling, 1980; Pourcho, 1981). In cat the interplexiform cell synapses onto rod bipolar cells in the outer plexiform layer (Kolb \& West, 1977; Ehinger, 1982) but not onto horizontal cells or photoreceptor terminals. However, very little is known at present about the electrophysiological and pharmacological properties of these cells; thus, the possibility of rod bipolar cell involvement in the production of the STR cannot be excluded. Also, the neurotransmitter released by cat horizontal cells is not known (Massey \& Redburn, 1987; Ehinger, 1982).

In agreement with some previous reports, we found that GABA had an enhancing effect on PII. These reports suggested that in amphibia (Dick \& Miller, 1985a) as well as in mammals (Dick \& Miller, 1985b) the enhancement of PII by GABA (plus ethanol) corresponds with an 
increase of distal $\mathrm{K}^{+}$released by depolarizing bipolar cell processes extending into the OPL. It was shown, in addition, that the effect did not result from summation with a reduced $a$-wave (fast-PIII). Our data in Fig. 11 rule out the possibility that the enhancement of PII results from a reduction of the STR (which has an opposite polarity). Figure 11c clearly shows a GABA-induced increase of PII, without a reduction of the STR in the presence of bicuculline (plus haloperidol). Thus, GABA seems to have at least one site of action in the distal retina where it augments the current generating mechanism of PII.

Although the method used in the present study does not allow for the identification of cells controlling the STR, our results support previous reports that implicate inner retinal cells in its production. Moreover, our results suggest that the retinal pathway that carries the rod driven STR near absolute threshold may be influenced by cells that use glycine and/or GABA as a neurotransmitter.

Acknowledgements-We thank Dr J. S. McReynolds for critically reading earlier versions of the manuscript, Miss Julie Casler for technical assistance, and Ms Linda J. Hosman for secretarial assistance. This work was supported by NIH grant RO1-EY06094 and a Core grant P30EYO7003. P. A. Sieving is the 1989-1990 Olga Keith Wiess Scholar of Research to Prevent Blindness, Inc.

\section{REFERENCES}

Bodis-Wollner, I., Marx, M. S. \& Ghilardi, M. F. (1987). The effect of haloperidol on the flash ERG in the monkey. Investigative Ophthalmology and Visual Science, 28 (Suppl.), 3, 409.

Bolz, J., Frumkes, T., Voigt, T. \& Wassle, H. (1985a). Action and localization of $y$-aminobutyric acid in the cat retina. Journal of Physiology, London, 362, 369-393.

Bolz, J., Thier, P., Voigt, T. \& Wassle, H. (1985b). Action and localization of glycine and taurine in the cat retina. Journal of Physiology, London, 362, 395-413.

Bonaventure, N., Wioland, N. \& Mandel, P. (1974). Antagonists of the putative inhibitory transmitter effects of taurine and GABA in the retina. Brain Research, 80 , $281-290$.

Bormann, J. (1988). Electrophysiology of GABA- $a$ and GABA- $b$ receptor subtypes. Trends in Neuroscience, 11 , $112-116$

De Vries, G. \& Friedman, A. H. (1978). GABA, picrotoxin and retinal sensitivity. Brain Research, 148, 530-535.

Dick, E. \& Miller, R. F. (1985a). Extracellular $\mathrm{K}^{+}$activity changes related to electroretinogram components. I. Amphibian (I-type) retinas. Journal of General Physiology, 85, 885-909.

Dick, E. \& Miller, R. F. (1985b). Extracellular $\mathrm{K}^{+}$activity changes related to electroretinogram components. II. Rabbit (E-type) retinas. Journal of General Physiology, 85, 911-931.
Dutar, P. \& Nicoll, R. A. (1988). A physiological role for GABA-b receptors in the central nervous system. Nature, London, 332, 156-158.

Ehinger, B. (1982). Neurotransmitter systems in the retina. Retina, 2, 305-321.

Famiglietti, E. V. (1983). On- and off-pathways through amacrine cells in mammalian retina: The synaptic connections of "Starburst" amacrine cells. Vision Research, 23, $1265-1279$.

Frishman, L. J. \& Steinberg, R. H. (1989) Light evoked increases in $\left[\mathrm{K}^{+}\right]_{0}$ in proximal portion of the dark adapted cat retina. Journal of Neurophysiology, 61, 1233 1243.

Gottlob, I., Wundsch, L. \& Tuppy, F. K. (1988). The rabbit electroretinogram: Effect of GABA and its antagonists. Vision Research, 28, 203-210.

Holmgren-Taylor, I, (1983). Electron microscopical observations on the indoleamine-accumulating neurons and their synaptic connections in the retina of the cat. Journal of Comparative Neurology, 208, 144-156.

Kamp, C. W. \& Morgan, W. W. (1981). GABA antagonists enhance dopamine turnover in rat retina in vivo. European Journal of Pharmacology, 69, 273-279.

Knapp, A. G. \& Schiller, P. H. (1984). The contribution of on-bipolar cells to the electroretinogram of rabbits and monkeys: A study using 2-amino-4-phosphonobutyrate (APB). Vision Research, 24, 1841-1846.

Kolb, H. \& Nelson, R. (1983). Rod pathways in the retina of the cat. Vision Research, 23, 301-312.

Kolb, H. \& Nelson, R. (1984). Neural architecture of the cat retina. In Osborne, N. N. \& Chader, G. J. (Eds.), Progress in retinal research (Vol. 3. pp. 21-60). New York: Pergamon.

Kolb, H. \& West, R. W. (1977). Synaptic connections of the intcrplexiform cell in the retina of the cat. Journal of Neurocytology, 6, 155-170.

Massey, S. C. \& Redburn, D. A. (1987). Transmitter circuits in the vertebrate retina. Progress in Neurobiology, 28, 55-96.

Massey, S. C., Redburn, D. A. \& Crawford, M. L. J. (1983). The effects of 2-amino-4-phosphonobutyric acid (APB) on the ERG and ganglion cell discharge of rabbit retina. Vision Research, 23, 1607-1613.

McGuire, G., Lukasiewicz, P. D. \& Werblin, F. (1989). Amacrine cell interactions under-lying the response to change in tiger salamander retina. Journal of Neuroscience, 9, 726-735.

Miller, R. F. \& Dacheux, R. F. (1983). Intracellular chloride in retinal neurons: Measurement and meaning. Vision Research, 23, 399-411.

Miller, R. F., Dacheux, R. F. \& Frumkes, T. E. (1977). Evidence for independent GABA and glycine releasing amacrine cells in mudpuppy retina. Science, 198, 748.

Miller, R. F., Frumkes, T. E., Slaughter, M. \& Dacheux, R. F. (1981). Physiological and pharmacological basis of GABA and glycine action on neurons of the mudpuppy retina. 11. Amacrine and ganglion cells. Journal of Neurophysiology, 45, 764-782.

Nakamura, Y., McGuire, B. A., \& Sterling, P. (1980). Interplexiform cell in cat retina: Identification by uptake of $\gamma-(3 \mathrm{H})-\mathrm{H}$ aminobutyric acid and serial reconstruction. Proceedings of the National Academy of Sciences, U.S.A., 208, 658-661.

Negishi, K., Teranishi, T. \& Kato, S. (1983). A GABA antagonist, bicuculline, exerts its uncoupling action on external horizontal cells through dopamine cells in carp retina, Neuroscience Letters, 37, 261-266. 
Nelson, R. (1982). AII amacrine cells quicken time course of rod signals in the cat retina. Journal of Neurophysiology, 47, 928-947.

Noell, W. K. (1954). The origin of the electroretinogram. American Journal of Ophthalmology, 28, 78-90.

O'Conner, P., Dorison, S. J., Watling, K. J. \& Dowling, J. E. (1986). Factors affecting release of 3H-dopamine from perfused carp retina. Journal of Neuroscience, 6 , 1857-1865.

Oyster, C. W., Takahashi, R. S., Cilluffo, M. \& Brecha, N. C. (1985). Morphology and distribution of tyrosine hydroxylase-like immunoreactive neurons in the cat retina. Proceedings of the National Academy of Sciences, U.S.A., 82, 6335-6339.

Pourcho, R. G. (1980). Uptake of $3 \mathrm{H}$-glycine and $3 \mathrm{H}$ GABA by amacrine cells in the cat retina. Brain Research, 198, 333-346.

Pourcho, R. G. (1981). Autoradiographic localization of (3H)-muscimol in the cat retina. Brain Research, 215, 187-199.

Pourcho, R. G. (1982). Dopaminergic amacrine cells in the cat retina. Brain Research, 252, 101-109.

Pourcho, R. G. \& Goebel, D. J. (1983). Neuronal subpopulation in cat retina which accumulate the GABA agonist 3H-muscimol: A combined Golgi and autoradiographic study. Journal of Comparative Neurology, 219, 25-35.

Pourcho, R. G. \& Osman, K. (1985). Starburst-like amacrine cells in cat retina are cholinergic. Society of Neuroscience, Abstr. 11, 1218.

Sieving. P. A. (1991). Retinal ganglion cell loss does not abolish the scotopic threshold response (STR) of the cat and human ERG. Clinical Vision Sciences, 6(2), in press.

Sieving, P. A. \& Nino, C. (1988). Scotopic threshold response (STR) of the human electroretinogram. Investiga tive Ophthalmology and Visual Science, 29, 1608-1614.

Sieving, P. A., Frishman, L. J. \& Steinberg, R. H. (1986). Scotopic threshold response of proximal retina in cat. Journal of Neurophysiology, 56, 1049-1061.

Sieving, P. A., Wakabayashi, K. \& Lemon, W. J. (1988). Current source density analysis of cat scotopic threshold response. Investigative Ophthalmology and Visual Science (Suppl.), 29, 103.

Sillman, A. J., Ito, H. \& Tomita, T. (1969). Studies on the mass receptor potential of the isolated frog retina. I. General properties of the response. Vision Research, 9 $1435-1442$.

Slaughter, M. M. \& Miller, R. F. (1981), 2-Amino-4phosphonobutyric acid: A new pharmacological tool for retina research. Science, 211, 182-185,

Starr, M. S. (1975). The effects of various amino acids, dopamine and some convulsants on the electroretinogram of the rabbit. Experimental Eye Research, 21, 79-87.

Sterling, P. (1983). Microcircuitry of the cat retina. Annual Review of Neuroscience, 6, 149-185.

Stockton, R. \& Slaughter, M. M. (1989). $b$-Wave of the electroretinogram: A reflection of on-bipolar cell activity. Journal of General Physiology, 93, 101-122.

Straschill, M. \& Perwein, L. (1969). The inhibition of retinal ganglion cells by catecholamines and gamma-aminobutyric acid. Pfiügers Archives, 3/2, 45-54.

Wachtmeister, L. (1980). Further studies of the chemical sensitivity of the oscillatory potential of the electroretinogram (ERG). 1. GABA- and glycine antagonists. Acta Ophthalmologica, 58, 712-725.

Wachtmeister, L. \& Dowling, J. E. (1978). The oscillatory potentials of the mudpuppy retina. Investigative Ophthalmology and Visual Science, 17, 1176-1188.

Wakabayashi, K., Gieser, J. \& Sieving, P. A. (1988). Aspartate separation of the scotopic threshold response (STR) from the photoreceptor $a$-wave of the cat and monkey ERG. Investigative Ophthalmology and Visual Science, 29, $1615-1622$.

Wassle, H., Schafer-Trenkler, I. \& Voigt, T. (1986). Analysis of a glycinergic inhibitory pathway in the cat retina. Journal of Neuroscience, 6, 594-604.

Wyszecki, G. \& Stiles, W. S. (1967). Color science. New York: Wiley.

Yonemura, D., Kawasaki, K., Yanagida, H., Tanabe, J., Kawaguchi, H. \& Nakata, Y. (1979). Effects of amino acids on oscillatory activities of the light evoked potentials of the retina and visual pathways. Japanese Journal of Ophthalmolagy Proceedings, I6th ISCEV, 339-353. 